\title{
Prevention program for fallings in elderly
}

\begin{abstract}
Introduction: It was noticed the increasing of the risk to fall in elderly. Prevention program could decrease this prevalence.
\end{abstract}

Objective: To identify the prevalence for falls in elderly active people and to verify the effectiveness of an intervention program to decrease the risk for falls.

Method: This is a cross-sectional, prospective, and quantitative study. Sixty volunteers, aged ranged 60 to 85 years $(70.07 \pm 7.02)$ from the community of a small city in northeast of Brazil wereselected. The Dynamic Gait Index (DGI)Brazilian brief versionand Timed Up and Go (TUG) was used to identify the risk for falls and the Cawthorne and Cooksey protocol was the baseline to prevention program.

Results: The DGI showed that $35.8 \%$ presented risk for falls and at the ending period, these scores decreased to $10.25 \%$ ( $\mathrm{p}$ value $=8 \mathrm{X} 10-5)$. The initial scores to TUG showed that $76.3 \%$ of the sample had a risk of falls, and $23.6 \%$ after the program(p Value $=6 \times 10-7$ ).

Conclusion: It was found that the risk for falls was higher in older elders and the prevention program reduced the risk of falls and improved gait and dynamic balance in this sample.

Keywords: aged, health of the elderly, postural balance, questionnaires, accidental falls
Volume 5 Issue 4 - 2020

\author{
Carlos Kazuo Taguchi,' Gecileide Silva \\ Beserra,' Raissa Valença de Souza Santos,' \\ Allan Robert da Silva, ${ }^{2}$ Brenda Carla Lima \\ Araújo,' Thales Rafael Correia de Melo \\ Lima, ${ }^{3}$ Aline Cabral de Oliveira,' Jacqueline \\ Pitanga Teixeira, ${ }^{4}$ Julianne Pitanga Teixeira ${ }^{5}$ \\ 'Speech Therapist and Audiology, Federal University of Sergipe, \\ Brazil \\ ${ }^{2}$ Statistical and Actuarial Sciences Departament, Federal \\ University of Sergipe, Brazil \\ ${ }^{3}$ Professional Postgraduate Program in Health Technological \\ Management and Innovation, Federal \\ ${ }^{4}$ University Hospital, Federal University of Sergipe, Brazil \\ ${ }^{5}$ University Hospital Audiology, Federal University of Sergipe, \\ Brazil
}

Correspondence: Carlos Kazuo Taguchi, Departamento de Fonoaudiologia, Universidade Federal de Sergipe,Avenida Marechal Rondon S/N. Bairro Rosa Elze, Zip Cod: 49700-000, São Cristóvão - SE - Brazil, Tel 55-079-397|-6805, Email carlostaguhi@hotmail.com

Received: June 23, 2020 | Published: July 07, 2020

\section{Introduction}

The senescence is an irreversible phenomenon and causes changes in the epidemiological morbidity and mortality profile. The elderly people are more susceptible to fall's events. Falls are common among older people and a major public health challenge ${ }^{1}$ and could be associated with the negative impact on the quality of life, mainly in females. ${ }^{2-4}$ The risk to falls can be reduced by preventionsprograms focused on balance exercises and strength training. ${ }^{3}$ This is the premise to development toreducing falling in senescence, through promotion programs and health prevention of the elderly. ${ }^{5-8}$

This study proposed to identify the prevalence of falls in a socially active elderly people and to verify the effectiveness of an intervention program based on Cawthorne and Cooksey's vestibular rehabilitation protocol developed over five weeks to decrease the risk for falls.

\section{Method}

This is prospective and clinical research approved by Ethical Committee (number 6232.00.000-107-10) of Federal University of Sergipe developed from 2018,July to November. Sixty-three socially active volunteers from the small city in northeast of Brazil, mean age $70.07( \pm 7.02)$ year were evaluated and submitted to prevention falls project. We performed the Dynamic Gait Index- Brazilian brief version9and Timed Up and Go tests10 to characterize and select this sample. All subjects were invited to participate in the prevention program, especially those with risk for falls. All volunteers were shared in four group with fifteen subjects and with trainees' assistance during the exercises performed in sitting, standing, trunk and head rotation and walking. It was used the Cawthorne and Cooksey's vestibular rehabilitation protocol developedover five weeks, one hour of intervention program. Those that participated over three weeks were evaluated with initial tests and composed the final sample.To statistical analysis it was used the SOFT R PROJECT: 3.12 program with Wilcoxon test. The significance level equal or less than $5 \%$ was adopted.

\section{Results and discussion}

The final statistical analysis included by 39 volunteers that presented risk to falls on DGI-Brazilian brief version and completed more than $60 \%$ attendance at activities. Before the intervention, it was observed that $35.8 \%$ presented risk to falls. The media score was 19,56 $( \pm 3,76)$ pointswith this tool. After the intervention, the media was $22,17( \pm 2,69)$ points and $10.25 \%$ presented risks yet. The Wilcoxon test showed significant $\mathrm{p}$-value $(8 \times 10-5)$.

On the TUG test, $76.3 \%$ of the sample presented risk for falls. At the first evaluation it was observed $13,07( \pm 4,540$ second as media. At the ending period, it was verified that $23.6 \%$ of the sample presented risks. The final media scores as $9,31( \pm 2,66)$ seconds with significant $\mathrm{p}$ value $(6 \times 10-7)$.

It was verified in another studie 3,4,6 that female gender and those over the age of seventy had a higher risk for falls, but another showed that female and seniors with more than 80 years presented higher risks. ${ }^{6}$ It could be justified because this gender is prone to major changes due to muscle weakness, osteoporosis, dizziness, vertigo, depression, and medication use. . $^{3,4}$

It was highlighted a massive percentage of theses seniors presented risk to falls in TUG test which was reported in another research. ${ }^{10,11}$ It means that active seniors could present risk to fall and prevention and educational program should be developed to increase health care for the elderlies. ${ }^{6,12,13}$ 
A sedentary lifestyle should increase the risk of falls in the elderly., ${ }^{4,610}$ The performance of physical activities had positive effects on postural stability and increase the balance, functional ability, coordination, and mobility. ${ }^{14}$ It was verified that Cawthorne and Cooksey exercises promoted a reduction in the risk of falls and decrease the possibility of future falls and improvement in balance in the elderly. ${ }^{6,4,12,13}$ It was verified the better performance on gait and functional balance in this sample demonstrated in another studies ${ }^{6,8,13}$ which contributes to decrease fallings.

The analysis of results agreed with other studies ${ }^{5-8,10-13}$ and the contributed to reducing for falling risks in the elderly.The study showed be effective and should be use as proposal in health primary care programs. ${ }^{6-8,13}$

\section{Conclusion}

It was found that the risk for falls was higher in older elders and the prevention program reduced the risk of falls and improved gait and dynamic balance in this sample.

\section{Acknowledgments}

None.

\section{Conflicts of interest}

The authors declare have no conflict of interest about the publication of this paper.

\section{References}

1. While AE. Falls and older people: understanding why people fall. $\mathrm{Br} J$ Community Nurs. 2020;25(4):173-177.

2. Bittar RSM, Oiticica J, Bottino MA, et al. Estudo epidemiológico populacional da prevalência de tontura na cidade de São Paulo. Braz $J$ Otorhinolaryngol. 2013;79(6):688-698.
3. Siqueira, FV; Fachini,LA; Silveira, DS, et al. Prevalence of falls in elderly in Brazil: a countrywide analysis. Cad Saúde Pública. 2011,27(9):18191826 .

4. Cruz DT, Ribeiro LC, Vieira MT, et al. Prevalencia de caídas y factores asociados en ancianos. Rev Saúde Pública. 2012;46(1): 138-146.

5. Ganz,DA, Latham NK. Prevention of falls in community-dwelling older adults. $N$ Engl J Med. 2020;382(8):734-743.

6. Cobos MF, Pariente EA, Enrique GS, et al. The effect of a falls prevention program in elderly people in primary health care. What does Tai Chi practice provide?. Rev Esp Salud Publica. 2019;93(1):e1-e12.

7. Taguchi CK, Santos TFO, Nascimento RS, et al. Eficácia de programa de prevenção de quedas em idosos. Disturbios Comum. 2016;28(2):286-294.

8. Ribeiro ASB, Pereira JS. Improved balance and reduced chance of falling in elderly women after cawthorne and cooksey exercises. Rev Bras Otorrinolaringol. 2005;71(1).

9. Taguchi CK, Costa ÉP, Alves LV, et al. Clinical application of dynamic gait index-brazilian brief version. Advances in Aging Research. 2018;7:113118 .

10. Podsiadlo D, Richardson S. The timed "up \& go": A test of basic functional mobility for frail elderly persons. J Am Geriatr Society. 1991;39:142-148.

11. Almeida ST, Soldera CLC, Carli GA, et al. Análise de fatores extrínsecos e intrínsecos que predispõem as quedas em idosos. Rev Assoc Med Bras. 2012;58(4):427-433.

12. Fernandes AMBL, Ferreira JJA, Stolt LROG, et al. Efeitos da prática de exercício físico sobre desempenho da marcha e da mobilidade funcional em idosos. Fisioter Mov. 2012;25(4):821-830.

13. Pagliosa, LC; Renosto, A. Effects of a health promotion and fall prevention program in elderly individuals participating in interaction groups. Fisioter Mov. 2014;27(1):101-109.

14. Dipietro L, Campbell WW, Buchner DM. Physical activity, injurious falls, and physical function in aging: an umbrella review. Medicine \& Science in Sports \& Exercise. 2019;51(6):1303-1313. 